\title{
Fatigue Strength of Electroplated Copper Thin Films under Uni-Axial Stress*
}

\author{
Naokazu MURATA ${ }^{* *}$, Kinji TAMAKAWA ${ }^{* *}$, Ken SUZUKI** and Hideo MIURA** \\ **Fracture and Reliability Research Institute, Graduate School of Engineering, Tohoku University, \\ Tohoku University, 6-6-11-716, Aoba Aramaki, Aobaku, Sendai, Miyagi 980-8579 \\ E-mail: naokazu.murata@rift.mech.tohoku.ac.jp
}

\begin{abstract}
Fatigue strength of electroplated copper thin films was measured under uni-axial stress. Two kinds of electroplated films were prepared for the fatigue test. One was a commercial film mainly used for interconnections in printed wiring boards. The other film was grown on a stainless steel substrate by using acid copper sulfate bath without any additive agent. The micro texture of each film was observed by using SEM (Scanning Electron Microscope) and SIM (Scanning Ion Microscope). It was found that the micro texture of each film was quite different with each other. The mechanical properties such as the yield stress, fracture elongation and Young's modulus of each film changed significantly from those of bulk copper depending on their micro structure. The low-cycle fatigue strength also varied drastically with each other, while the high-cycle fatigue strength was almost same. The fracture surfaces were observed by SEM after the fatigue test. It was found that there were two fracture modes under the fatigue test. One was a typical ductile fracture, and another was brittle one even under the fatigue load higher than its yield stress. Transgranular crack propagation was observed when the ductile fracture occurred. On the other, Intergranular crack growth appeared when the brittle fracture occurred. These results clearly indicated that the fatigue strength of electroplated copper thin films varies depending on their micro structure.
\end{abstract}

Key words: Micromechanics, Fatigue, Fractography, Thin Film, Electroplating, Copper

\section{Introduction}

Electronic products such as mobile phones and PCs have been miniaturized continuously and their functions have been improved drastically [1]. The miniaturization of the size of semiconductor devices is indispensable for improving their electronic performance. As a result, the minimum width of thin film interconnections in the devices has become less than $100 \mathrm{~nm}$. However, such a miniaturization causes the increase of the resistance of the thin film interconnections and thus, increases both Joule heat and signal delay. In addition, the increase of the current density in the interconnections for high speed operation degrades their life because it enhances electromigration. Therefore, electroplated copper thin films have started to be applied to not only interconnections in printed wiring board, but also thin film interconnections in semiconductor devices because of its low electric resistance and high thermal conductivity.

However, mechanical properties of the electroplated copper thin films, such as Young's modulus and the tensile strength were found to vary drastically comparing with those of the conventional bulk material. For example, the Young's modulus of the films varied from about $20 \mathrm{GPa}$ to $120 \mathrm{GPa}$ depending on the micro texture of the films. The fracture strain 

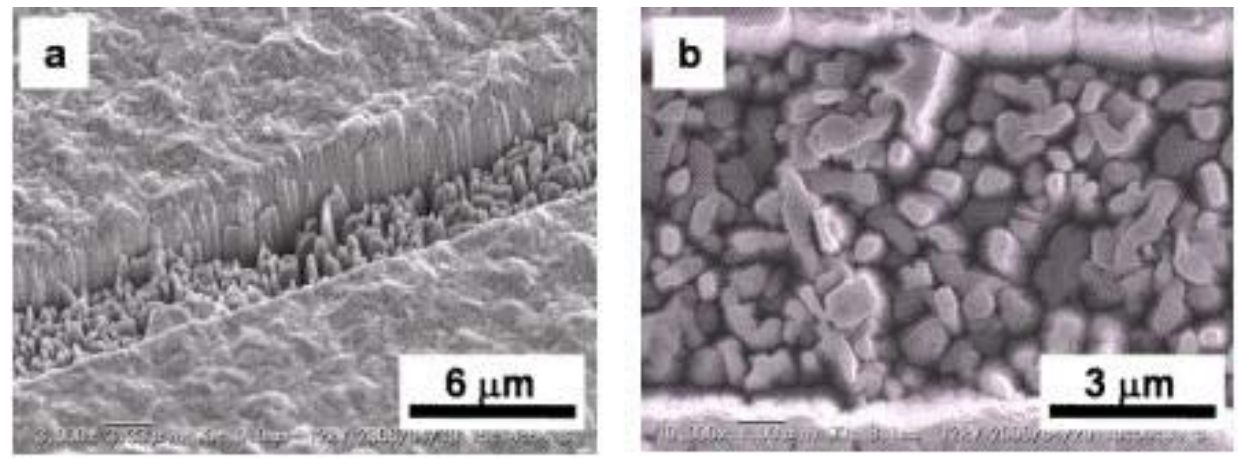

Fig. 1 Scanning electron micrographs of an electroplated copper thin film. (a) Bird's-eye view of the film partially etched-off by ion beams. (b) Planer view of the film partially etched-off by ion beams. Fine columnar grains are observed clearly.

also varied from about 0.01 to 0.3 . [2]-[5] In addition, it was found that the Young's modulus of the films along the thickness direction measured by a nano-indenter varied significantly depending on the depth of the indentation. [4] These results were mainly attributed to the columnar grains of the electroplated films as shown in Fig. 1. The electroplated copper thin films mainly consisted of columnar grains with the diameter of a few hundred $\mathrm{nm}$ and the height of about a few $\mu \mathrm{m}$. The grain boundaries between the columnar grains seemed to be rather weak because they were easily etched off by ion beams as shown in Fig. 1. Such a micro columnar structure with weak grain boundaries changes mechanical properties of the electroplated copper thin films significantly from those of bulk material. For example, Young's modulus of the electroplated copper thin films showed strong anisotropy due to the cooperative grain boundary sliding [6] and the magnitude of the modulus was much lower than that of bulk material as mentioned above. Also, the fluctuation of the effective Young's modulus of the films at their surfaces was rather large due to the micro texture. These variation and fluctuation of mechanical properties of the electroplated copper thin films may degrade the reliability of electronic devices seriously. From this point of view, it is necessary to clarify the fatigue strength of the electroplated copper thin films and to establish techniques to control their mechanical properties for assuring the reliability of electronic products.

Though various methods for evaluating the fatigue strength of thin films have been proposed [7]-[9], these methods require very complicated test systems. Therefore, we applied a simple uni-axial fatigue test for evaluating the fatigue strength of the electroplated copper thin films. Two kinds of the electroplated copper thin films with different micro texture were used for the fatigue test to discuss the effect of the micro texture of the films on their fatigue strength.

\section{Experimental methods}

\subsection{Sample preparation}

Two kinds of the test specimens of the electroplated copper thin films were prepared. One was a commercial film used for interconnections in printed wiring boards. The other film was made in the authors' laboratory. In this paper, the commercial film is designated as "Film A", and the self-made film is designated as "Film B". The thickness of the Film A was $35 \mu \mathrm{m}$, and that of the Film B was $10 \mu \mathrm{m}$. The composition of the plating bath used for the electroplating of the Film B was controlled by diluting the $\mathrm{CuO}$ powder of $80 \mathrm{~g}$, the $\mathrm{H}_{2} \mathrm{SiO}_{4}$ of $186 \mathrm{~g}$ with the purified water of $1000 \mathrm{ml}$. Since the current density during the electroplating of thin film interconnections is varied from $10 \mathrm{~mA} / \mathrm{cm}^{2}$ to $100 \mathrm{~mA} / \mathrm{cm}^{2}$ depending on products, the test film was electroplated on stainless steel under the constant 

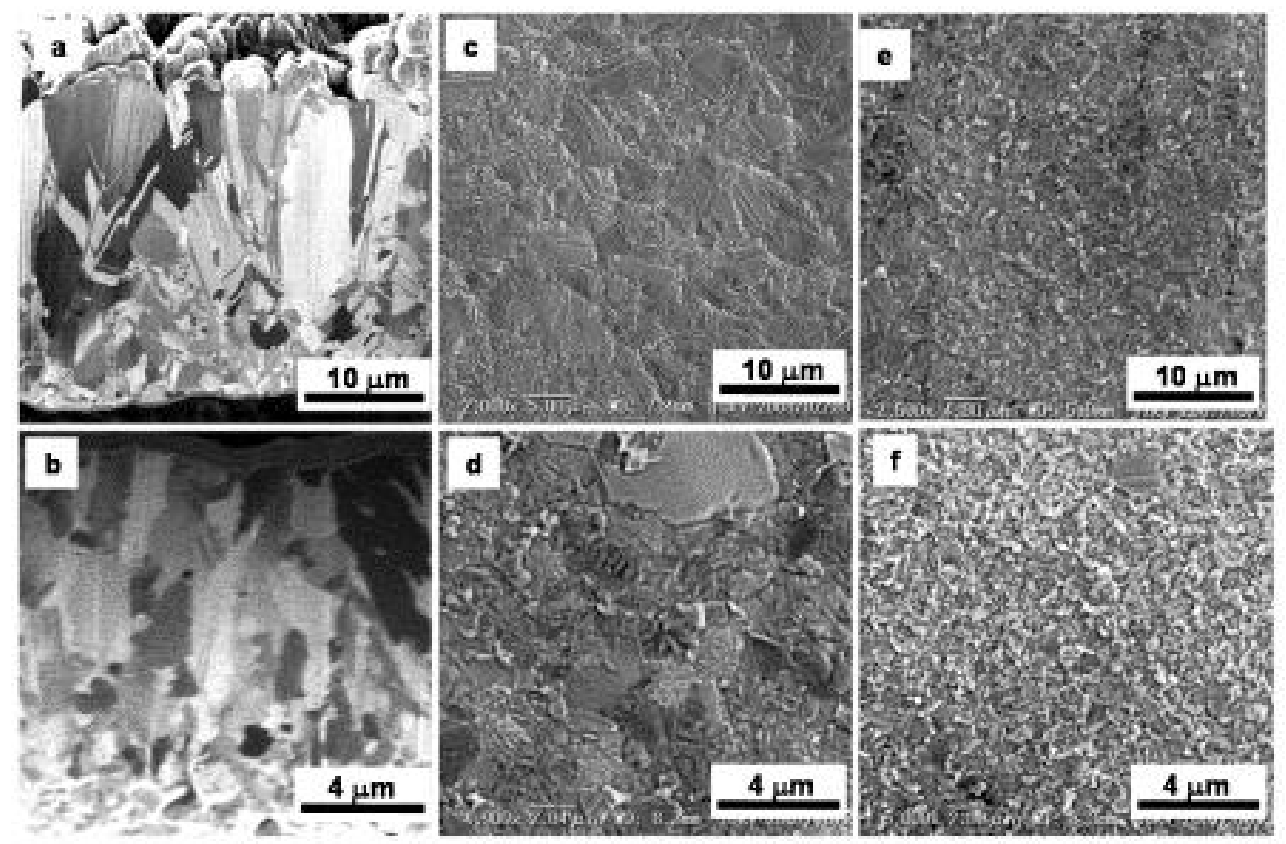

Fig.2. Micro-texture of Film A and Film B. (a) SIM image of the cross section of Film A. (b) SIM image of the cross section of Film B. (c) SEM image of the top surface of Film A. (d) SEM image of the top surface o Film B. (e) SEM image of the bottom surface of Film A. (f) SEM image of the bottom surface of Film B

current density of $30 \mathrm{~mA} / \mathrm{cm}^{2}$ at $30{ }^{\circ} \mathrm{C}$.

Figure 2 summarizes the micro texture of each film. It was found that both Film A and Film B mainly consisted of columnar grains from as shown in Figs. 2(a) and 2(b). In addition, the average grain size of the bottom area was finer than that of the top surface area. In the Film A, the average grain size around the top surface area was about $5 \mu \mathrm{m}$ as shown in Fig 2 (c). The grain size in the bottom area was less than $1 \mu \mathrm{m}$ as shown in Fig. 2 (e). The Film A, therefore, mainly consisted of large columnar grains with smaller grains near the bottom area. Similarly, the top side of the Film B consisted of columnar grains with the average grain size of about 1-5 $\mu \mathrm{m}$ as shown in Fig. 2 (d). The bottom side of this film also consisted of finer grains with the average grain size less than $1 \mu \mathrm{m}$ as shown in Fig. 2 (f).

\subsection{Mechanical properties of the test samples}

Figure 3 shows the stress-strain curves of Film A and Film B obtained by a tensile test. Even though they were both electroplated thin films, their tensile properties were quite different with each other. Both the Young' modulus and tensile strength of the Film B were about twice of those of Film A. But the fracture strain of Film A was about five times higher than that of Film B. In addition, Film A shows work hardening and thus, the fracture mode of Film A is ductile. On the other hand, Film B fractured without clear plastic deformation. This film was rather brittle. The deformation without work-hardening was reported in materials that consist of the microscopic grains. [5]

The fracture surfaces of both films after the tensile test were observed by SEM as shown in Fig. 4. The fracture surface of Film A (Fig. 4(a)) was rather rough and some dimples are observed on the surface. It shows a typical ductile fracture surface. On the other hand, the fracture surface of Film B (Fig. 4(b)) was flat. Dimples or necking due to ductile deformation is not observed on the surface. This sample shows brittle fracture surface clearly as was expected from its stress-strain curve shown in Fig. 3. Therefore, these two kinds of films show quite different mechanical characteristics with each other. Both the electroplated copper thin films consisted of the microscopic columnar grains as shown in 


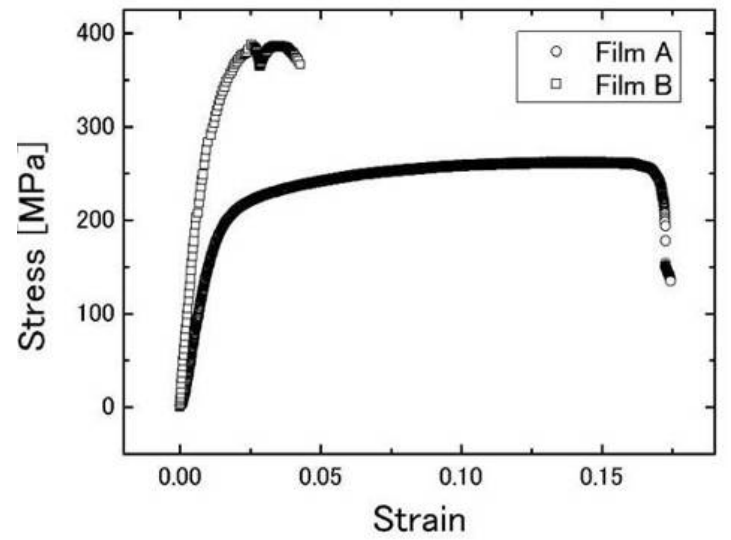

Fig.3. Stress-strain curves of Film A and Film B under uni-axial tensile load

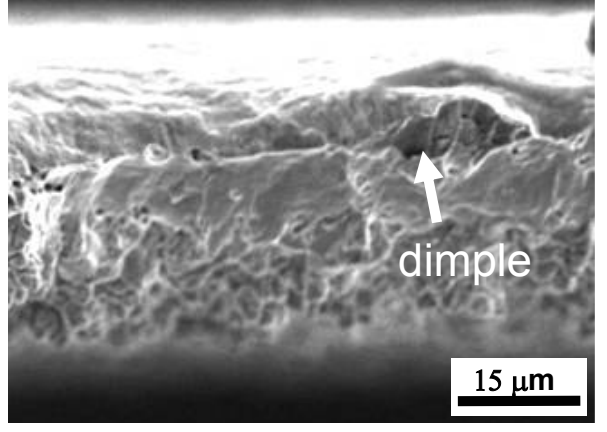

(a)

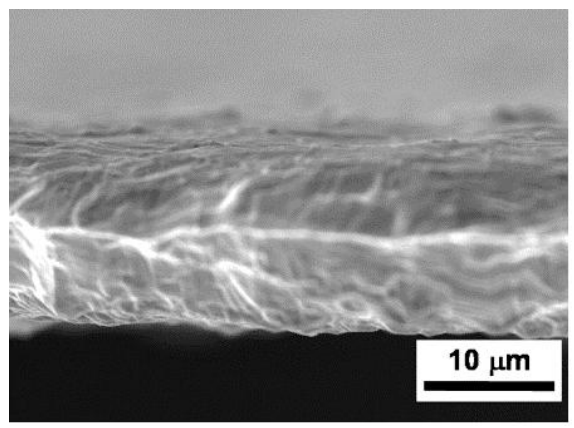

(b)

Fig. 4 SEM images of cross-section of fracture surface of (a) Film A, and (b) Film B after the tensile test

Fig. 2. Since the average diameters of the columnar grains of both films are close, the main reason for the difference of their mechanical properties should be attributed to the strength of their grain boundaries. When the strength of grain boundaries of electroplated thin films is weak, cracks propagate along the grain boundaries of the columnar grains, and the films show brittle fracture mode. [5]

Table 1 summarizes their mechanical properties. The measured mechanical properties of the electroplated films were different from bulk materials significantly. The Young's modulus of the films was varied from $1 / 4$ to $1 / 7$ of that of bulk material. In addition, the elongation, i.e., their fracture strain was varied from $1 / 3$ to $1 / 10$ of that of bulk material, even though their tensile strength was higher than that of bulk material. The mechanical properties of the electroplated copper thin films are strongly affected by their micro texture. As mentioned before, they are mainly consisted of fine columnar grains with weak grain boundaries. The cooperative grain boundary sliding occurs in the films under tensile load perpendicular to the columnar grains, and it decreases the effective Young's modulus of the structure. On the other hand, both the yield stress and tensile strength of the film which consists of the fine columnar grains increase, since the yield strength of polycrystalline metals usually increases with the decrease of average grain size based on Hall-Petch relationship. However, the weak grain boundaries make the film brittle and decrease the elongation of the film significantly. Therefore, the mechanical properties of the electroplated copper thin film vary drastically depending on the micro texture.

The fatigue test of these films were performed by using Magnetic Micro Testing system MMT-101NV-10 (product made in Shimazu Corporation, Capacity is $100 \mathrm{~N}$ ). The films were attached on a jig as shown in Fig. 5. The controlled stress was applied to the film and the deformation of the film during the test was measured by a laser interferometer. 
Table 1. Mechanical properties of electroplated copper thin films

\begin{tabular}{cccccc}
\hline & $\begin{array}{c}\text { Thickness } \\
{[\mu \mathrm{m}]}\end{array}$ & $\begin{array}{c}\text { Young's modulus } \\
{[\mathrm{GPa}]}\end{array}$ & $\begin{array}{c}\text { Yield stress } \\
{[\mathrm{MPa}]}\end{array}$ & $\begin{array}{c}\text { Tensile stress } \\
{[\mathrm{MPa}]}\end{array}$ & $\begin{array}{c}\text { Elongation } \\
{[\%]}\end{array}$ \\
\hline \hline Film A & 35 & 18 & 170 & 260 & 17 \\
Film B & 10 & 30 & 270 & 385 & 4 \\
Park et al [9] & 15 & 72 & 358 & 462 & 4.5 \\
Kim et al [10] & 18 & 82.5 & 279 & 336 & \\
Bulk & & 130 & 59 & $200-250$ & $40-60$ \\
\hline
\end{tabular}

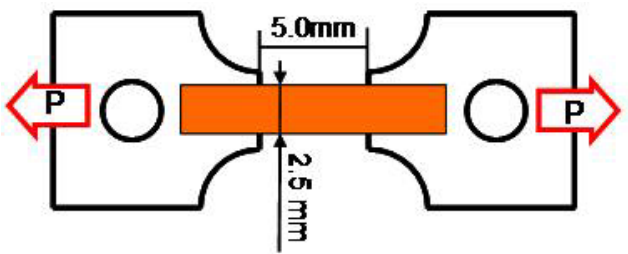

Fig. 5. Schematic illustration of the test sample for fatigue test

The fatigue condition was as follows. The cyclic uni-axial tensile load was applied to the films using a sine wave and the stress ratio was fixed at 0.1 . The frequency of the fatigue test was fixed at $1.5 \mathrm{~Hz}$.

\section{Experimental results and discussion}

Figure 6 summarizes the fatigue strength of Film A and Film B. The fatigue strength of Film A was higher than that of Film A in low cycle region. This was mainly due to the difference in the yield stress between the two films. The fluctuation of the measured data of Film B was much larger than that of Film A, because the fracture mode of Film B was more brittle than that of Film A, as it will be referred to in detail later. In high cycle region, the fatigue strength of both films was almost the same. In addition, it should be noted that since the yield stresses of Film A and Film B were $170 \mathrm{MPa}$ and $270 \mathrm{MPa}$, respectively, the fatigue fracture of both films occurred under the applied stress that was much lower than their yield stress. In particular, the fatigue limit of Film B was less than one third of its yield stress. These results indicate that the fatigue mechanism in low cycle region was different from that in high cycle region. Thus, the fracture mode of both films was discussed more in detail.

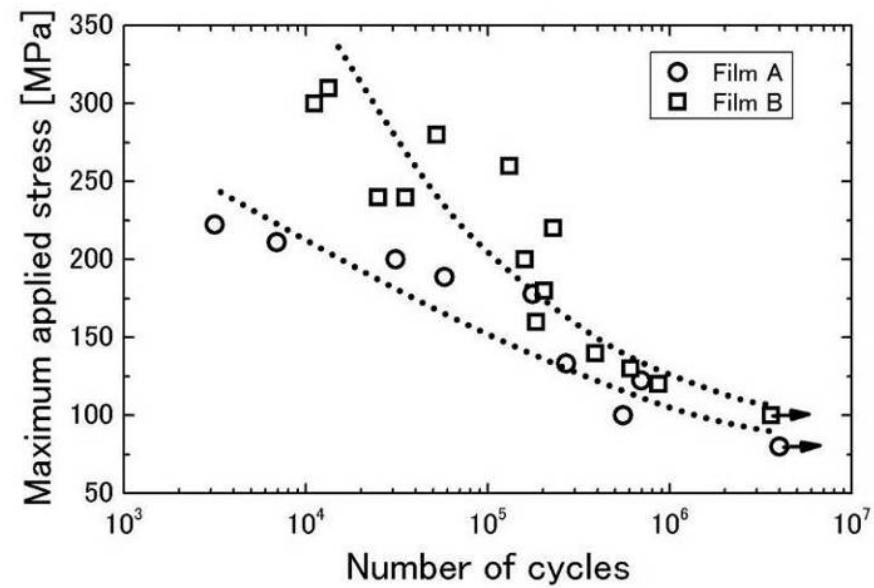

Fig. 6. S-N curves of Film A and Film B 


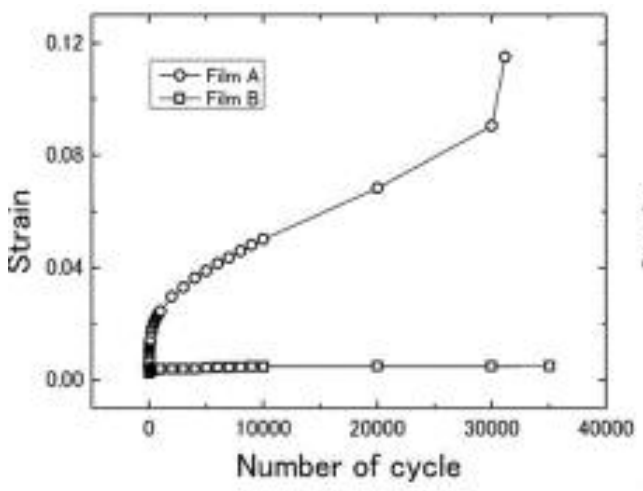

(a)

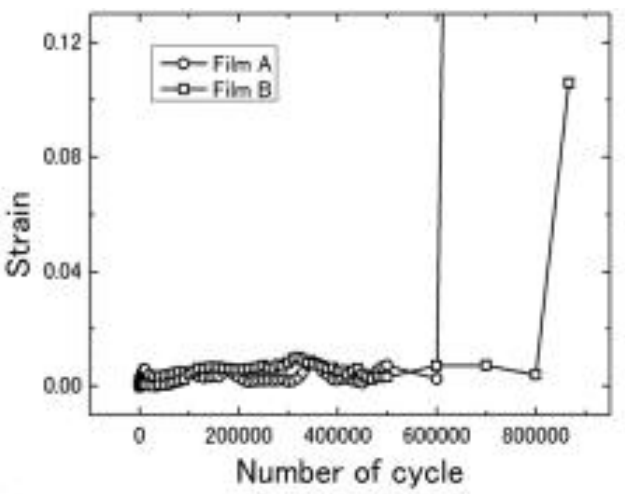

(b)

Fig. 7. Changes of strain of Film $A$ and film $B$ during fatigue test. (a) In low cycle region. The stress amplitude applied to Film A was $180 \mathrm{MPa}$, and that to Film B was $240 \mathrm{MPa}$. (b) In high cycle region. The stress amplitude applied to Film A was $110 \mathrm{MPa}$, and that to Film B was $120 \mathrm{MPa}$.
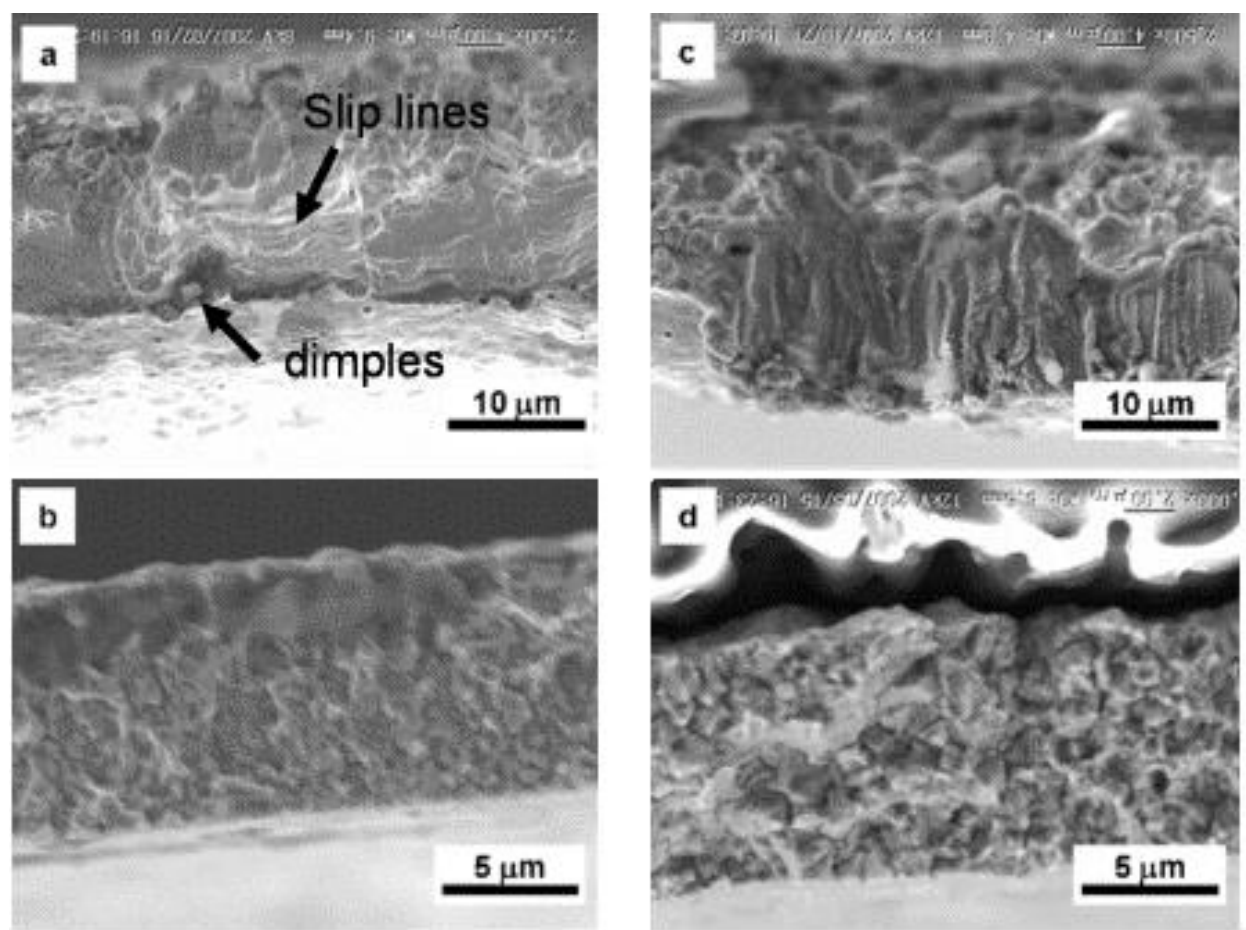

Fig. 8. SEM image showing fracture surfaces of Film A and Film B after the fatigue test. (a) Cross-section of Film A fractured in the low cycle region. (b) Cross-section of Film B fractured in the low cycle region. (c) Cross-section of Film A fractured in high cycle region.. (d) Cross-section of Film B fractured in high cycle region.

Figure 7(a) shows the changes of the total strain of both films during the fatigue test in low cycle region. The Film A showed typical clear plastic deformation in low cycle fatigue. However, Film B did not show plastic deformation during the test and it showed rapid fracture. Similar brittle fracture mode occurred in both films in high cycle region as shown in Fig. 7(b). No clear plastic deformation was observed in both films before their sudden fracture.

These results indicate that there are two fracture modes in film A under cyclic load. One is conventional typical fatigue fracture based on plastic deformation of the whole film. Another mode is brittle fracture without plastic deformation. This means that the dominant 
mechanism of fatigue fracture of this film changed from transgranular cracking to intergranular cracking depending on the applied stress amplitude. On the other hand, the fracture mode of Film B was always brittle one even when the applied stress exceeds its yield stress. Thus, the fatigue crack propagated along grain boundaries in Film B regardless of the applied stress amplitude. The reason for the wide fluctuation of the measured data in low cycle region can be attributed to this brittle fracture mode.

In order to clarify the fracture mode of both films under cyclic load, their fracture surfaces were observed by using a scanning electron microscope. Figure 8 shows the fracture surfaces of both films. Some slip lines and dimples were observed on the surface of Film A fractured in low cycle region as shown in Fig. 8(a). Therefore, the fatigue crack should have propagated in grains and the final break was ductile fracture. On the fracture surface obtained in high cycle region, however, no striations or dimples were observed as shown in Fig.8(c). Some columnar-like grains are observed on the surface and this result indicates that the fracture occurred at grain boundaries. These two micrographs clearly indicate that there are two fracture modes in Film A and the main mode is determined by the applied stress amplitude.

On the other hand, there were no striations and dimples on the fracture surfaces of Film B as shown in Fig.8 (b) (d), even when the applied stress amplitude was much higher than its yield stress. This means that the fatigue crack propagated mainly on the fracture surface without macroscopic plastic deformation of the whole film. Only small cracks were observed on the surfaces. These micrographs show that the brittle fracture occurred in Film $B$ regardless of the applied stress amplitude as was expected based on the results shown in Figs. 7(a) and 7(b).

Figure 9 shows the scanning electron micrographs of the plane view of the top surfaces of the electropolished films after the fatigue test. In these micrographs, the cyclic tensile load was applied up and down as it is indicated in the figure. It was found that the grains elongated drastically along the direction of the tensile loading in Film A fractured in low cycle region as shown in Fig. 9(a). This micrograph clearly indicates that plastic

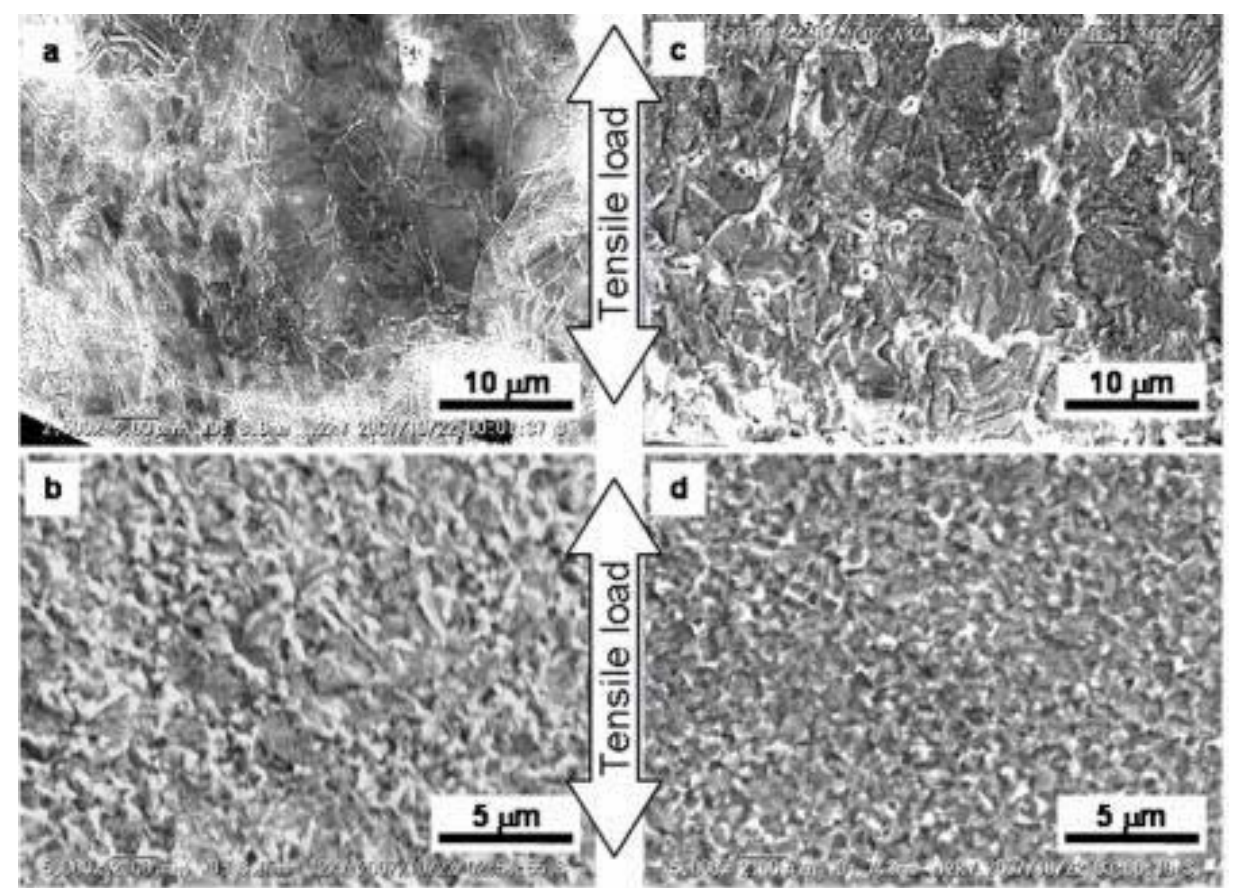

Fig. 9. SEM images showing top surfaces of Film A and Film B after the fatigue test. (a) Top surface of Film A fractured in low cycle region. (b) Top surface of Film B fractured in low cycle region. (c) Top surface of Film A fractured in high cycle region.. (d) Top surface of Film B fractured in high cycle region. 
deformation occurred all over the film. However, the grains didn't show plastic deformation when the film was fractured in high cycle region as shown in Fig. 9(c). On the other hand, no plastic deformation of grains was observed in Film B regardless of the number of cycles to failure as shown in Figs. 9(b) and 9(d). These results also indicate that the fatigue crack propagated only along grain boundaries in Film B without any macroscopic plastic deformation of grains and thus, this film showed brittle fracture.

The variation of the fracture mode is caused by the micro texture of the electroplated copper thin films, in other words, fine columnar grains with weak or brittle grain boundaries. When the strength of grain boundaries is low, cracks can easily propagate along the grain boundaries regardless of the amplitude of the applied stress. Stress intensity factor should be the dominant factor of the crack propagation. Plastic deformation can occur even in the fine columnar grains when the strength of grain boundaries is higher than the average yield strength of the film. Therefore, the characteristics of grain boundaries in the electroplated copper thin films dominate its fracture mode and the fatigue strength of the films.

\section{Conclusions}

Fatigue strength of the electroplated copper thin films was measured under the uni-axial cyclic tensile loading. Mechanical properties of the electroplated copper thin films differ from those of bulk materials significantly. The strength of the electroplated copper thin films was a strong function of the micro texture of the films. Since the electroplated copper thin films mainly consisted of fine columnar grains with weak grain boundaries, their Young's modulus decreased drastically due to the cooperative grain boundary sliding of the micro texture. The constraint of the movement of dislocations caused by the fine grains increased the yield stress of the films. The elongation, in other words, the fracture strain of the films decreased drastically due to brittle fracture caused by the weak grain boundaries. The fluctuation of the strength of the grain boundaries caused the large fluctuation of mechanical properties of the electroplated copper thin films because the micro texture of he films varied significantly depending on the condition of electroplating.

The fatigue strength of the electroplated thin films also varied drastically depending on the condition of electroplating, in other words, the micro texture of the films. There were two fracture modes under cyclic load. One was typical fatigue fracture based on the plastic deformation of the whole film. In this fracture mode, both striation patterns and dimples were observed on the fracture surfaces. Another fracture mode was brittle fracture. The fatigue cracks propagated along the grain boundaries of fine columnar grains and thus, no striation patterns or no dimples were observed on the fracture surfaces. Such a brittle fracture mode increased the fluctuation of the fatigue strength of the films. In addition, the brittle fatigue fracture occurred in the films with weak grain boundaries even when the applied stress amplitude stress was much lower than the yield stress of the films. Therefore, it is very important to control the characteristics of grain boundaries of electroplated copper thin films for assuring its long-term reliability.

\section{References}

[1] International Technology Roadmap for Semiconductors 2005.

[2] M. Kiuchi, Y. Isono, and S. Sugiyama, Proc. of Mechanical Engineering Congress, 2004 Japan. Vol. 1, (2004), pp. 367-368.

[3] H. Miura, K. Sakutani, and K. Tamakawa, Key Engineering Materials, Vols. 353-358, (2007), pp. 2954-2957.

[4] M. Otani, K. Sakutani, K. Tamakawa, K. Suzuki, and H. Miura, Proc. of the ASME Pacific Rim Techni-cal Conference and Exhibition on Integration and Packaging of Micro, 
Nano, and Electronic Systems, No. IPACK2007-33261 (CDROM), (2007.7), pp. 1-7.

[5] K. Tamakawa, K. Sakutani, and H. Miura, Journal of The Society of Materials Science Japan, Vol. 56, No. 10, (2007.10), pp. 907-912.

[6] H. Muto and M. Sakai, Key Engineering Materials, Vol. 166, (1999), pp. 103-108.

[7] B.X. Xu, Z.F. Yue, J. Weang, Mechanics of Materials, 39 (2007) 1066-1080.

[8] G.P. Zhang, C.A. Volkert, R. Schwaiger, R. Monig, O. Kraft. Microelectronics Reliability, Vol. 47, (2007), pp. 2007-2013.

[9] J.-H. Park, J.-H. An, Y.-J. Kim, Y.-H. Huh, H.-J. Lee. Mat.-wiss. u. Werkstofftech. Vol. 39, No. 2, (2008).

[10] D.I. Kim, Y.-H. Huh, D.J. Kim, Y.H. Lee , C.D. Kee. Journal of Materials Processing Technology, Vols. 187-188, (2007), pp. 232-235. 